\title{
Compartimentação geomorfológica do leque fluvial do rio Negro, borda sudeste da Bacia do Pantanal (MS)
}

\author{
Bruna Medeiros Cordeiro ${ }^{1}$, Edna Maria Facincani', Antonio Conceição Paranhos Filho², \\ Vitor Matheus Bacani ${ }^{1}$ \& Mario Luis Assine ${ }^{3}$
}

\begin{abstract}
Resumo O leque do Negro é um sistema deposicional aluvial que vem sendo construído pelo rio Negro na borda sudeste do Pantanal desde o Pleistoceno. Sua superfície apresenta feições geomorfológicas e drenagem atuais e reliquiares. O rio Negro flui de leste para oeste e integra a Bacia Hidrográfica do Alto Paraguai (BAP), sendo afluente da margem esquerda do rio Paraguai. A bacia de drenagem do rio Negro é um grande anfiteatro de erosão localizado no planalto de Maracaju-Campo Grande, esculpido em rochas paleozóicas e mesozóicas da Bacia do Paraná e em rochas neoproterozóicas do Grupo Cuiabá. O contato entre o planalto e a planície é marcado por escarpa retilínea de direção NNE. O rio Negro apresenta, no planalto, comportamento obsequente em relação ao mergulho das camadas da Bacia do Paraná. A evolução geomorfológica do leque do Negro teve início com a construção de um lobo antigo na saída do planalto, de provável idade pleistocênica, seguido de avulsão para SE e formação do lobo pré-atual, que termina na vazante Santa Clara. O sítio deposicional holocênico é representado pelo lobo atual, formado sobre depósitos distais do megaleque do Taquari, e por uma planície de meandros embutida em vale inciso na porção superior do leque. Terrenos com inúmeras lagoas, semelhantes às da Nhecolândia, ocorrem entre os lobos, constituindo formas relictas preservadas dentro da área do leque do rio Negro.
\end{abstract}

Palavras-chave: rio Negro, leque fluvial, Bacia do Pantanal.

\begin{abstract}
Geomorphological zonation of the Negro river fluvial fan, southeastern border of the Pantanal Basin. The Negro fluvial fan is a depositional system located on the southeastern border of the Pantanal wetland and has been evolving since the Pleistocene. Its surface exhibits modern and relict geomorphological features, such as channels and paleochannels. The Negro River flows westward and belongs to the Upper Paraguay drainage basin. Theater-headed valleys characterize the catchment area on the Maracaju-Campo Grande Plateau, where the Negro River shows an obsequent behavior in relation to Paleozoic and Mesozoic sedimentary strata of Parana basin. A conspicuous NNE escarpment is the natural limit between the source area on the plateau and the depositional setting on the Pantanal wetland. The geomorphological zonation allowed to establish an evolution started in the late Pleistocene when unconfined flows given rise to formation of a proximal lobe. During a period dominated by erosion an incised valley has cut older deposits on the upper fan. Sedimentation during Holocene times has been taken place on the modern distal distributary fan lobe and on the meander belt that aggraded the incised valley.
\end{abstract}

Keywords: Negro river, fluvial fan, Pantanal Basin.

INTRODUÇÃo Situado entre os paralelos $15^{\circ}$ e $20^{\circ}$ $\mathrm{S}$ e os meridianos $55^{\circ}$ e $59^{\circ} \mathrm{W}$, o Pantanal Mato-Grossense é uma das mais importantes planícies alagáveis do mundo (Junk et al. 2006). Coincide aproximadamente com a área de uma bacia sedimentar quaternária, que se encontra embutida da depressão da Bacia do Alto Paraguai (BAP). O trato deposicional é caracterizado por inúmeros leques aluviais, cujas águas são coletadas pela planície fluvial do rio Paraguai, que é o rio-tronco do sistema. O primeiro grande leque identificado dentro deste conjunto foi o do Taquari (Braun 1977). Sua identificação só foi possível com o uso de imagens de satélite e de radar, pois o leque apresenta grandes dimensões geográficas, com área de cerca de $50.000 \mathrm{~km}^{2}$. Imagens de satélite permitiram a identificação de outros sistemas de leques aluviais de grandes dimensões (Tricart 1988, Ab'Saber 1988).

Os leques aluviais constituem sistemas deposicionais de baixo gradiente hidráulico, com canais de padrão distributário orientados radialmente em relação ao ápice, resultando feições geomorfológicas em forma de leque ou semi-cone. Nas regiões intertropicais, como no caso da Bacia do Alto Paraguai (BAP), os rios desempenham papel essencial para o desenvolvimento de leques dominados por rios meandrantes e/ou de baixa sinuosidade (Stanistreet \& McCarthy 1993).

1 - UFMS/CPAQ, Departamento de Geociências, Aquidauana (MS), Brasil. E-mails: brunageo_ufms@hotmail.com, emfacincani@bol.com.br, bacani_ufms@yahoo.com.br

2- UFMS/CCET, Departamento de Hidráulica e Transporte, Cidade Universitária, Campo Grande (MS), Brasil.

E-mail: toniparanhos@gmail.com

3 - Unesp/IGCE, Departamento de Geologia Aplicada, Rio Claro (SP), Brasil. E-mail: assine@rc.unesp.br 
Para ocorrer sedimentação em forma de leque, deve haver mudança no gradiente topográfico do rio e alargamento de seu vale, o que geralmente ocorre quando um rio deixa uma área de planalto e passa a correr numa planície, onde há espaço de acomodação para que a sedimentação ocorra. A dinâmica sedimentar é controlada pela interação de fatores alogenéticos (movimentos tectônicos, clima e mudanças na condição hidráulica do sistema) e autogenéticos (construção de barras, rompimento de diques marginais, avulsão fluvial), dando origem a morfologias deposicionais com perfis longitudinais côncavos e transversais convexos.

Em estudo regional sobre a sedimentação atual no Pantanal, Assine (2003) passou a utilizar a denominação megaleques fluviais para designar os sistemas distributários do Pantanal. A denominação megaleque fluvial vem sendo utilizada em inúmeros trabalhos para designar grandes sistemas distributários, devendo ser aplicada para sistemas com áreas entre $10^{3} \mathrm{e} 10^{5} \mathrm{~km}^{2}$ (Leier et al. 2005). Este é o caso do megaleque fluvial que o rio Paraguai está construindo na borda norte do Pantanal (Assine \& Silva 2009).
Dentre os sistemas deposicionais atuais do Pantanal, o megaleque do Taquari é o mais extenso e, sem dúvida, o mais conhecido (Assine \& Soares 2004, Assine 2005, Assine et al. 2005, Zani 2008).

O megaleque fluvial do Taquari coalesce, na sua borda sul, com os leques do Aquidauana e do Taboco (Facincani et al. 2006 e Facincani, 2007). Na sua borda sudeste existe um outro sistema distributário, ainda não descrito na literatura, formado pelo rio Negro, que tem sua bacia de drenagem no Planalto de Maracaju-Campo Grande.

O leque fluvial do rio Negro representa assim uma feição geomorfológica expressiva e importante na borda sudeste da bacia sedimentar do Pantanal. O presente trabalho tem por objetivo caracterizar sua geomorfologia, com ênfase no reconhecimento de lobos deposicionais e no estabelecimento dos eventos e processos que atuaram na configuração da paisagem.

Localizado no Estado de Mato Grosso do Sul, o leque aluvial do rio Negro está situado entre coordenadas $19^{\circ} 15^{\prime} \mathrm{S}$ e $19^{\circ} 45^{\prime}$ de latitude $\mathrm{S}$ e $55^{\circ} 00^{\prime} \mathrm{W}$ e $56^{\circ} 00^{\prime}$ de longitude $\mathrm{W}$. $\mathrm{O}$ acesso é possível através da MS-419, conhecida localmente como Estrada do Taboco, que margeia o lado leste da área estudada. (Fig. 1).

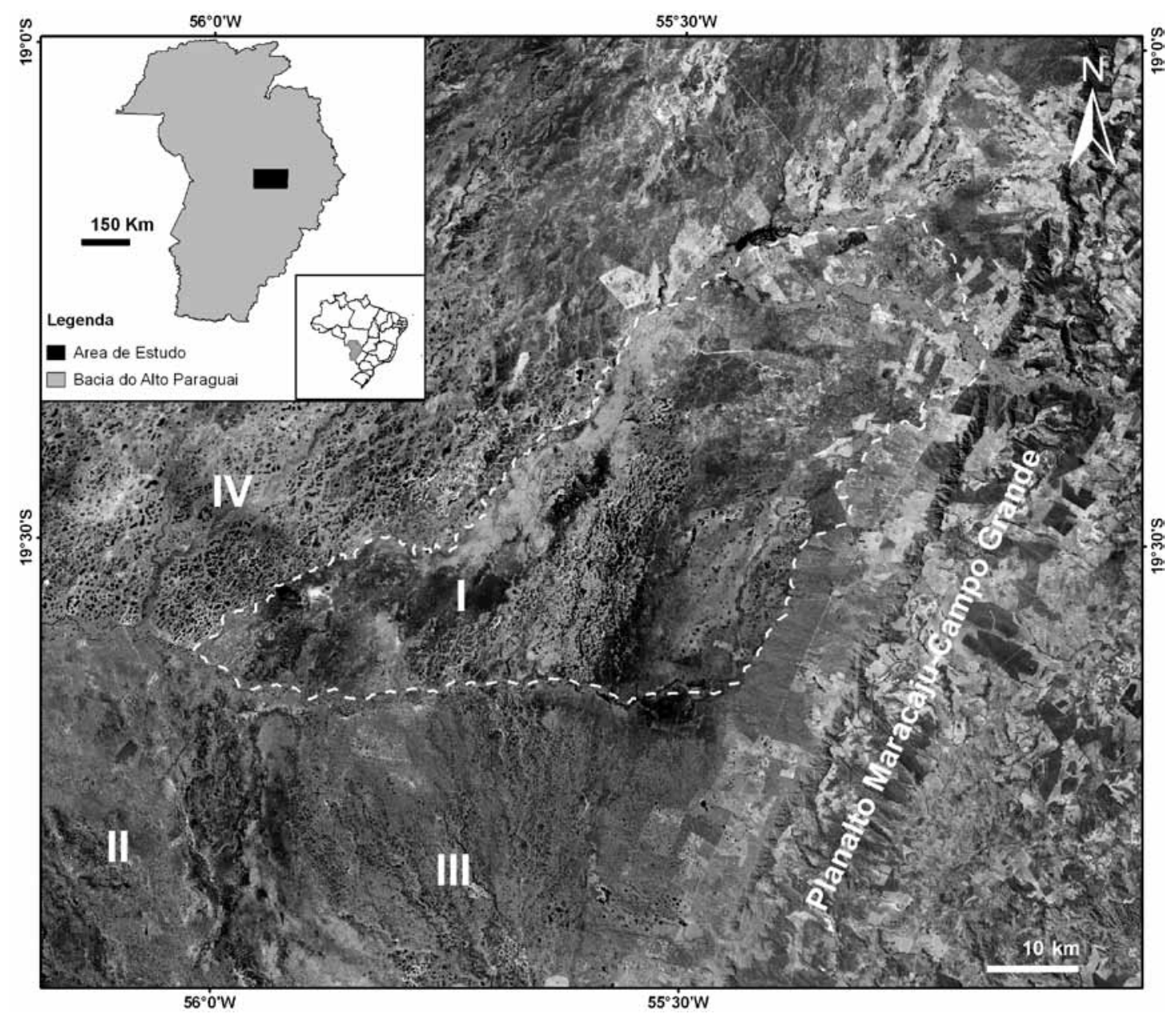

Figura 1 - Localização do leque do rio Negro (I), com indicação dos leques coalescentes do Taquari (II), Taboco (III) e Aquidauana (IV). (Imagem Landsat ETM+, Geocover circa 2000, composição falsa-cor RGB, NASA, https://zulu.ssc.nasa.gov/mrsid/). 
MATERIAIS E MÉTODOS Para a compartimentação geomorfológica da área estudada, foram utilizadas imagens orbitais do programa LANSAT TM e ETM+ (Land Remote Sensig Satelitte), disponíveis no site da NASA (National Aeronautics and Space Administration), correspondentes às cenas 225/073, 225/074, $226 / 073$ e $226 / 074$, todas corrigidas geometricamente.

Imagens Landsat 5/TM de 2007, com resolução espacial de $30 \mathrm{~m}$, foram analisadas em composição falsa-cor RGB (bandas 4, 5 e 3). A banda 3 (vermelho) capta o intervalo do espectro eletromagnético de 0,63 a 0,69 um, discrimina perfis e espécies de vegetação, permite análise litológica e entalhe dos cursos fluviais. A drenagem é bem representada pela banda 4 (infravermelho próximo), pois a alta absorção de energia mostra corpos d'água em tonalidades escuras. A banda 5 (infravermelho médio) discrimina a umidade no solo, sendo esta uma informação relevante na identificação de áreas mais úmidas no sistema de leque. Cenas do LANDSAT 7/ETM+ de 2001 também utilizadas no trabalho. A banda 8 , pancromática, possui resolução espacial de 15 metros, o que permitiu um trabalho com escala de maior detalhe, além de apresentar sensibilidade à morfologia do terreno (Paranhos Filho, 2008).

Para o reconhecimento de lobos deposicionais foram utilizados critérios morfológicos, baseados na orientação e truncamento de paleocanais, como os utilizados na compartimentação do megaleque do Taquari por Assine (2003) e Zani et al (2006). Além da hidrografia atual, foram reconhecidos padrões distributários da paleodrenagem, que permitiram identificar pontos de mudanças do curso fluvial e identificar diferentes lobos com base no padrão dos paleocanais. $\mathrm{O}$ traçado das redes de drenagem pré-atual e atual possibilitou a interpretação da cronologia relativa dos lobos deposicionais que compõem o leque do Negro.

Para subsidiar a delimitação do leque aluvial do rio Negro e identificação de suas geoformas deposicionais, foram analisadas e interpretadas fotos aéreas do recobrimento realizado em 64/66 pela Diretoria do Serviço Geográfico do Exército (DSGE), escala de 1: 60.000. Para a validação dos dados e interpretações foram realizadas duas campanhas de campo, incluindo um sobrevôo, durante as quais as formas interpretadas foram reconhecidas e documentadas fotograficamente, e os verificados os processos erosivos e deposicionais atuantes na área.

RESULTADOS E DISCUSSÃO Os trabalhos realizados permitiram caracterizar a existência e definir os limites do leque fluvial do Rio Negro. Os sedimentos depositados no leque têm área-fonte na bacia de drenagem, situada no planalto de Maracaju-Campo Grande, região leste da planície do Pantanal (Fig. 2).

O leque está sendo construído na planície o Pantanal e apresenta formato alongado na direção NESW. Seu limite oeste é dado pela ocorrência dos depósitos aluviais e lacustres da Baixa Nhecolândia, pertencentes ao megaleque do Taquari. Seu limite sul, com os leques do Taboco e do Aquidauana, é definido pela vazante Santa Clara e pelo próprio rio Negro, quando este deflete para oeste e passa a correr numa planície de meandros (Fig. 1).

O limite leste do leque é aproximadamente paralelo à escarpa do planato, mas dela é separado por uma rampa de depósitos mapeados como coluvionares. Tais depósitos são interpretados como depósitos de fluxo de detritos, formados em leques aluviais dominados por fluxos de gravidade.

Os padrões de drenagem e os elementos morfológicos da paisagem permitiram compartimentar a superfície do leque, tendo sido reconhecidos três lobos deposicionais e um cinturão de meandros porção superior do leque (Fig. 3). O leque do rio Negro se desenvolveu sobre depósitos distais do megaleque do Taquari, que ficaram preservados como formas relictas, dentro da área do leque do rio Negro, representadas por pequenas lagoas, de formas variadas, semelhantes às da Nhecolândia.

Bacia de drenagem A bacia de drenagem do rio Negro está situada no planalto de Maracaju-Campo Grande e tem área de aproximadamente $2.350 \mathrm{~km}^{2}$. No planalto o rio Negro flui de leste para oeste, em sentido contrário ao do mergulho das camadas das unidades paleozóicas e mesozóicas da Bacia do Paraná, de forma que pode ser classificado como rio obsequente.

$\mathrm{O}$ rio forma um grande anfiteatro de erosão, entalhado sobre rochas mesozóicas da Formação Botucatu, paleozóicas dos grupos Rio Ivaí (Formação Alto Garças), Paraná (formações Furnas e Ponta Grossa) e Itararé (Formação Aquidauna) e neoproterozóicas do Grupo Cuiabá e do Granito Rio Negro. É um rio de leito rochoso, com vale encaixado e corredeiras, que muda esta característica para jusante e passa a correr numa planície de meandros antes de entrar no Pantanal.

O sistema de drenagem é tributário e o rio corta as escarpas do planalto em vale de direção WNW. Ao atingir a planície do Pantanal, o rio passa a ser um rio essencialmente aluvial, atuando como agente de deposição dos sedimentos erodidos na bacia de drenagem. Na saída do planalto o rio está construindo um leque fluvial, cujos compartimentos, descritos nos itens seguintes, permitem esboçar uma evolução geomorfológica, que apresenta semelhanças com a do megaleque do Taquari, descrita por Assine e Soares (2004).

Leques dominados por fluxos gravitacionais Leques dominados por fluxos gravitacionais formam-se próximos as escarpas da borda do Planalto de Maracaju-Campo Grande, a leste do leque do rio Negro. Estes leques apresentam larguras entre 5 e $10 \mathrm{~km}$, estão associados a pequenos córregos que drenam o planalto e podem ser reconhecidos em fotografias aéreas e imagens de sensores remotos devido ao padrão radial de drenagem. Os vários leques coalescem formando uma rampa de piemonte, com largura em torno de $8 \mathrm{~km}$, alongada na direção norte-sul.

Predominam fácies de fluxos de detritos, depósitos mal selecionados com matriz arenosa e presença de seixos e matacões dispersos, localmente laterizados 


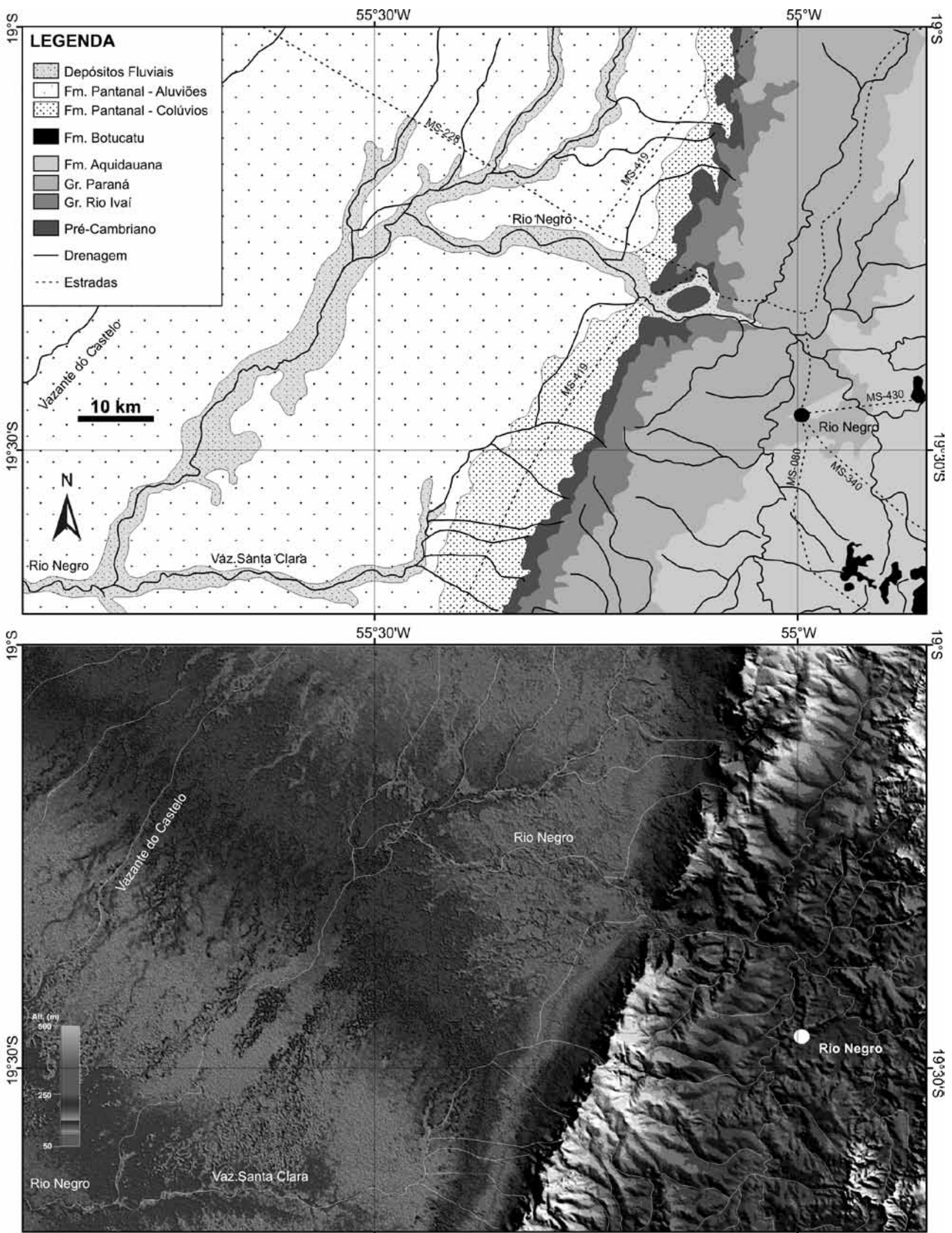

Figura 2 - Área estudada: A) Mapa geológico (Lacerda Filho 2006); B) modelo digital de elevação construido com dados SRTM/NASA.

(Fig. 4). Estas fácies afloram em algumas ravinas e em pequenos cortes da rodovia MS-419, no trecho que liga a cidade de Aquidauana à de Rio Negro.
Lobos deposicionais do Rio Negro Leques são caracterizados pela presença de um ou mais lobos deposicionais. Os lobos são feições morfológicas deposicio- 

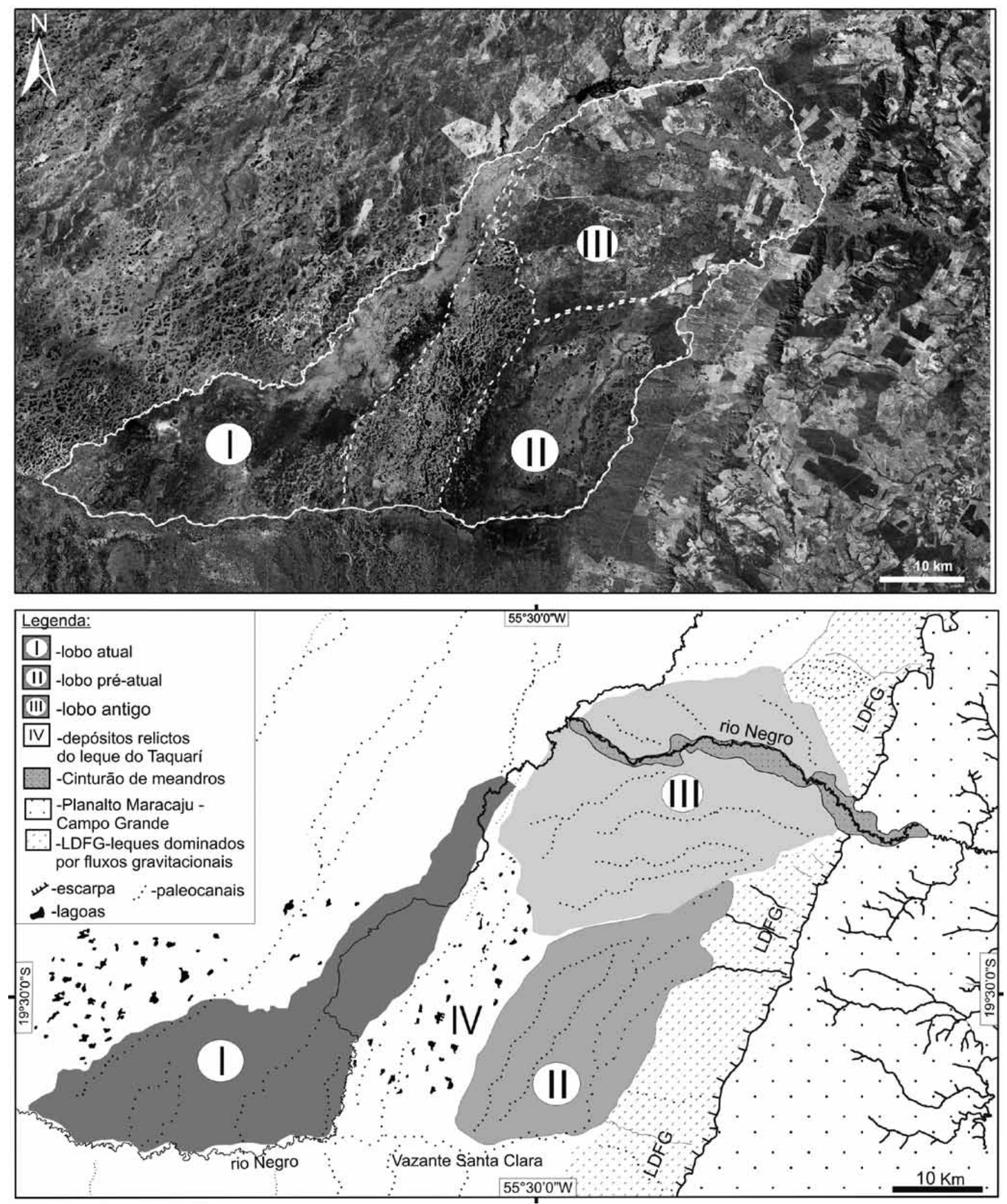

Figura 3 - Compartimentos geomorfológicos do leque do rio Negro.

nais, com ápice no ponto onde o rio alimentador começa a apresentar bifurcações e o sistema de drenagem torna-se distributário. Muitos dos canais distributários recebem, no Pantanal Mato-Grossense, as denominações de corixos e vazantes. A presença de canais distri- butários e a ocorrência de perda d'água para a planície durante as inundações causam redução na capacidade de transporte e conseqüente deposição de sedimentos.

Lobos são feições morfológicas características de sistemas deposicionais distributários como os leques 

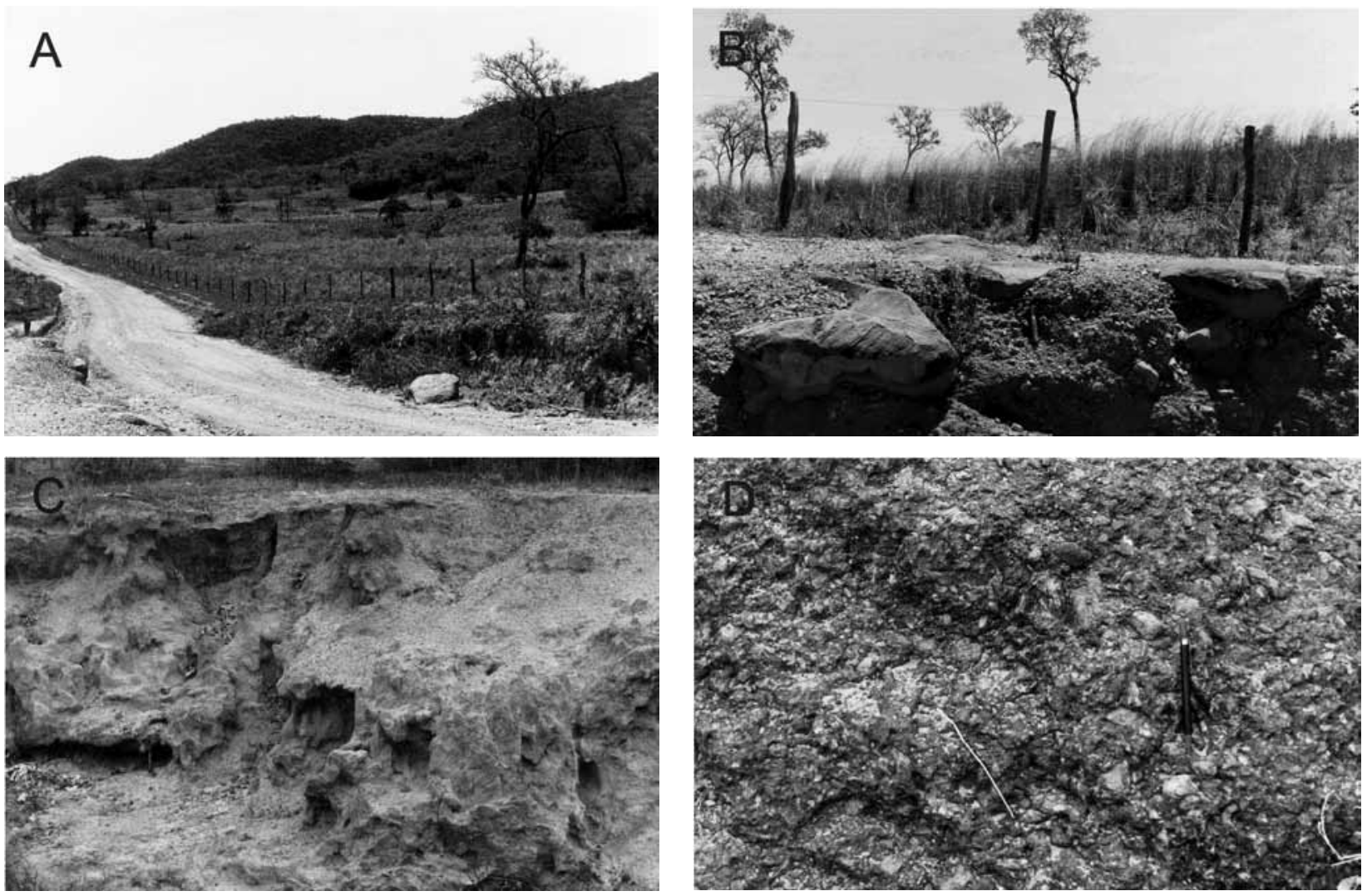

Figura 4 - Leques dominados por fluxo gravitacionais associados às escarpas da borda do Pantanal: A) expressão geomorfológica como rampa de piemonte; B) paraconglomerado sustentado por matriz arenosa; C) arenitos friáveis maciços; D) conglomerados com cimento de óxido de ferro (laterizados).

aluviais. No leque do rio Negro foram identificados dois lobos distais, um ativo (atual) e um abandonado (pré-atual), entre os quais estão preservadas geoformas de lagoas pertencentes à franja do leque do Taquari. Foi também reconhecido e delimitado um lobo mais antigo, situado na porção proximal do leque com ápice na saída do planalto (Fig. 3).

O lobo distributário atual (I) é alongado na direção NE-SW e se estende por área de aproximadamente $717 \mathrm{~km}^{2}$. Seu ápice foi definido no ponto em que os diques marginais apresentam rompimentos (crevasses) e perdem expressão morfológica, com desconfinamento do fluxo e perda d'água para a planície. Apresentando baixo gradiente topográfico, na superfície do lobo dominam processos de deposição por fluxos em lençol durante as enchentes (Fig. 5). Para jusante, o rio progressivamente se estreita e perde expressão, dando lugar a inúmeros pequenos e erráticos cursos d'água (corixos), com canais meandrantes, muitas vezes anastomosados. O nível freático é alto, resultando numa imensa planície úmida, com inundações sazonais de longa duração.

O lobo pré-atual (II) está situado na parte distal do leque, separado do lobo atual pelo enclave de lagoas da Nhecolândia dentro do leque do rio Negro. É um lobo em fase de dissecação, nele predominando processos fluviais erosivos. Nele se destaca um canal erosivo tributário conectado à vazante Santa Clara, que define o limite sul do leque. Este canal, que coleta as águas dos leques coalescentes situados no sopé das escarpas do planalto, provavelmente é o antigo canal principal do rio Negro.

O lobo mais antigo (III) apresenta morfológica típica de leque, com ápice na saída do planalto e paleocanais distributários radiais, visíveis em imagens de satélite (Fig. 3) e claramente delineados em modelo digital de elevação construído com dados SRTM (Fig. 2). A superfície do lobo encontra-se em estado de degradação, o que é sobretudo evidenciado pela presença de um vale entrincheirado (inciso), que o corta longitudinalmente.

Cinturão de meandros $\mathrm{O}$ cinturão de meandros está embutido dentro do vale inciso que corta a porção superior do leque, onde se situa o lobo mais antigo (Fig. 6). O cinturão apresenta extensão de cerca de $30 \mathrm{~km}$, pois se estende à montante para dentro do planalto, encaixado no vale que dá acesso ao Pantanal, onde é caracterizado pela presença de barras em pontal. O rio Negro apresenta larguras de 15 a $30 \mathrm{~m}$, com diques marginais cobertos por mata ciliar. Canais de alta sinuosidade, antigos leitos do rio Negro, agora abandonados, estão presentes na planície que tem largura entre 1,5 e $3,0 \mathrm{~km}$ e densa cobertura vegetal. Os terraços marginais que definem o vale inciso apresentam desnível de uns poucos metros em relação à planície atual do rio, suficientes para que as águas não extravasem para fora da planície durante as 

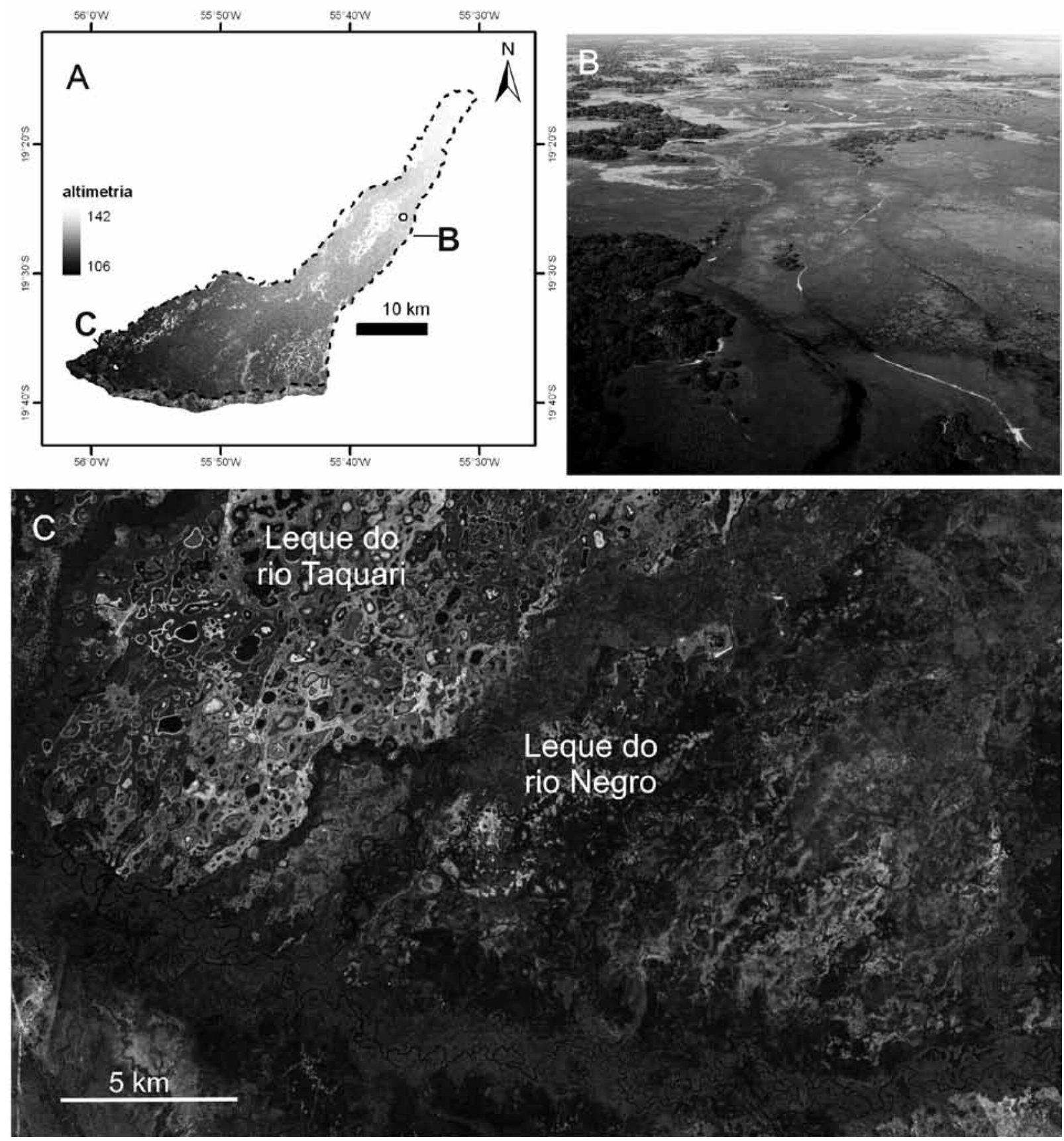

Figura 5 - Lobo distributário atual: A) altimetria; B) canal distributário no ápice em foto aérea oblíqua; C) franja do leque no contato com o leque do Taquari (oeste) e Rio Negro (sul).

cheias. $\mathrm{O}$ vale inciso apresenta controle estrutural principal NW e secundário NE, e o rio apresenta tendência de correr na direção NW próximo à margem direita do vale, o que sugere controle de tectônica atual.

CONCLUSÃO O leque do Negro constitui feição geomorfológica ativa na borda sudeste da bacia sedimentar do Pantanal, definido e descrito pela primeira vez neste trabalho. Localizado no médio curso do rio Negro, este sistema deposicional foi compartimentado geomorfologicamente, tendo sido identificados um lobo atual e dois abandonados, um pré-atual e um mais antigo, este último cortado por um vale inciso na por- ção proximal do leque.

Relações morfológicas dos compartimentos mapeados permitiram esboçar a evolução do leque. Após a formação do lobo mais antigo, que tem ápice na saída do planalto e padrão de drenagem radial a partir dele, ocorreu avulsão do canal principal, que passou a fluir para sudeste, dando origem ao lobo pré-atual na parte distal do sistema. Por correlação com feições semelhantes encontradas no leque do Taquari (Assine 2003), é atribuída, tentativamente, idade neopleistocênica para estes lobos abandonados.

Depois da formação do lobo pré-atual, o leque foi palco de eventos de rebaixamento do perfil 

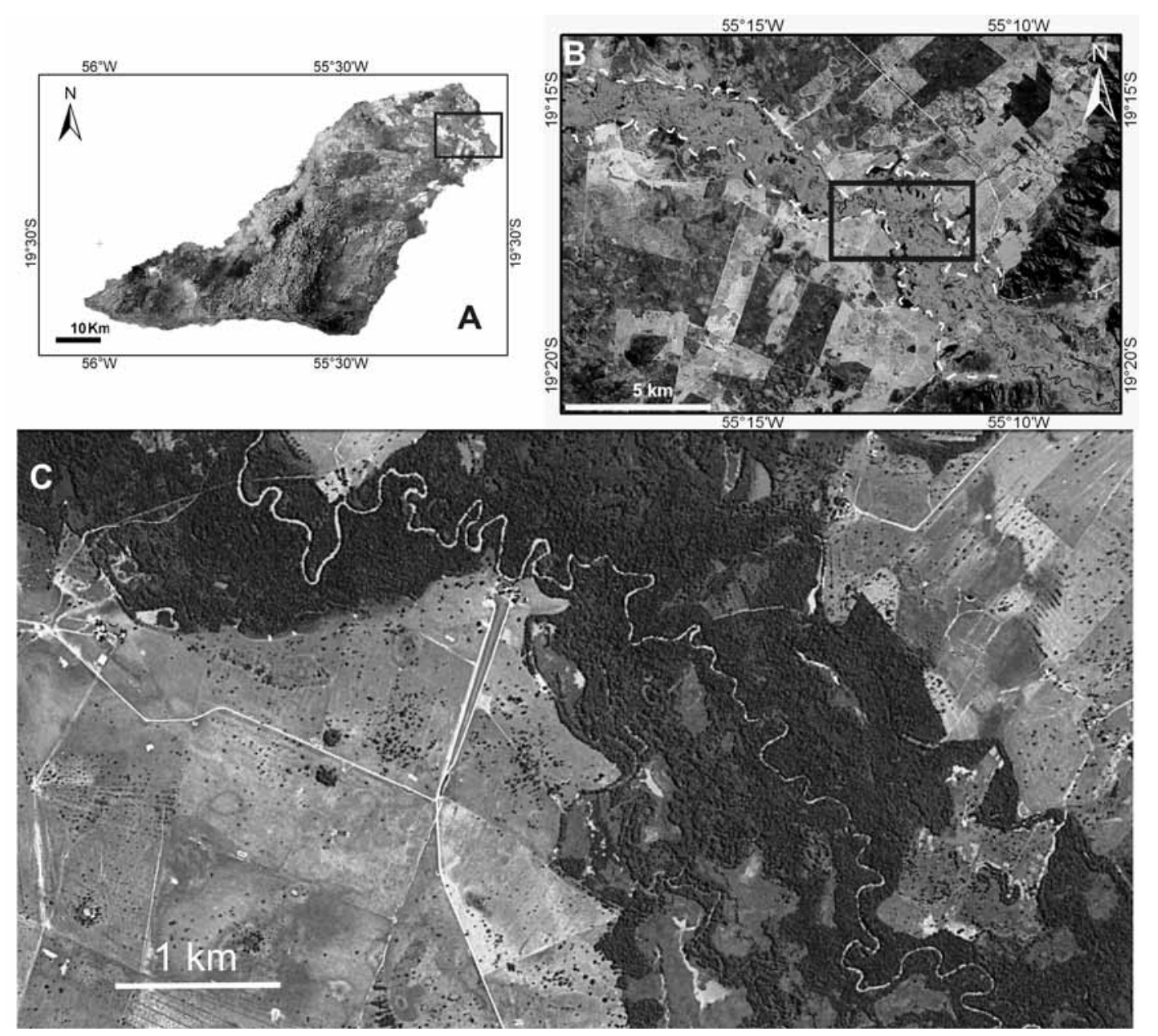

Figura 6 - Cinturão de meandros em vale inciso na porção superior do leque: A)localização do vale no leque do Negro, B) Cinturão de meandros na porção proximal do leque, C) foto em detalhe do cinturão de menadros.

de equilíbrio, que causaram incisão na superfície do leque, originando, na sua porção superior, um vale estreito que se encontra entrincheirado em depósitos do lobo mais antigo. Dissecação também ocorreu na porção distal, com a desintegração parcial de paisagem de lagoas, semelhante àquela da Nhecolândia, cujas geoformas ficaram preservadas como relictos dentro do leque do rio Negro.

A retomada de processos de sedimentação, já no Holoceno, promoveu a formação do lobo atual e agradação fluvial no vale inciso, dando origem ao atual cinturão de meandros existente na porção superior do leque.

O estabelecimento desta sucessão de eventos só foi possível graças à aplicação de geotecnologias, que permitiram a identificação do leque do rio Negro e sua compartimentação geomorfológica. Ressalta- se também que a compreensão dos processos sedimentares e dos depósitos de leques fluviais, como o do Negro, é de extrema importância para entender a origem e evolução da paisagem pantaneira. Por último, merece ser enfatizado que a cronologia relativa dos eventos, aqui apresentada, constitui a base para trabalhos futuros de caracterização e datação dos depósitos, necessários para reconstituição mais precisa dos eventos ocorridos na parte sul do Pantanal, do Pleistoceno tardio ao recente.

Agradecimentos Os autores externam seus agradecimentos à UFMS pelo apoio à pesquisa; ao $\mathrm{CNPq}$ pela concessão de bolsa PIBIC para Bruna M. Cordeiro e bolsa PQ para Mario L. Assine (308724/20062); e à FAPESP pelo apoio às pesquisas no Pantanal Mato-Grossense (2007/55987-3).

\section{Referências}

Ab'Saber A. N. 1988.O Pantanal Mato-Grossense e a teoria dos refúgios. Revista Brasileira de Geografia, 50 (Espe- cial Centenário, tomo 2):9-57.

Assine M.L. 2003. Sedimentação na Bacia do Pantanal Ma- 
to-Grossense, Centro-Oeste do Brasil. Rio Claro, Tese de Livre-Docência, Instituto de Geociências e Ciências Exatas, Universidade Estadual Paulista (Unesp), 106 p.

Assine M.L. 2005. River avulsions on the Taquari megafan, Pantanal wetland, Brazil. Geomorphology, 70:357-371.

Assine M.L. \& Silva A.S. 2009. Contrasting fluvial styles of the Paraguay River in the northwestern border of Pantanal wetland, Brazil. Geomorphology, 113:189-199.

Assine M.L. \& Soares P.C. 2004. Quaternary of the Pantanal, west-central Brazil. Quaternary International, 114:2334.

Assine M.L., Padovani C.R., Zacharias A.A., Angulo R.J., Souza M.C. 2005. Compartimentação geomorfológica, processos de avulsão fluvial e mudanças de curso do Rio Taquari, Pantanal Mato-Grossense. Revista Brasileira de Geomorfologia, 6:97-108.

DIRETORIA DO SERVIÇO GEOGRÁFICO DO EXÉRCITO (DSGE) 1966. Foto aérea. Escala 1:60.000. Brasília. Fx 316, n 51577.

Lacerda Filho J.V., Brito R.S.C., Silva M.G., Oliveira C.C., Moreton L.C., Martins E.G., Lopes R.C., Lima T.M., Larizzatti J.H., Valente C.R. 2006. Geologia e Recursos Minerais do Estado de Mato Grosso do Sul. Goiânia, CPRM/SICME, Escala 1:1.000.000, 121 p. e mapas.

Facincani E.M., Assine M.L., Silva A., Zani H., Araújo B.C., Miranda G.M. 2006. Geomorfologia fluvial do leque do rio Aquidauana, borda sudeste do Pantanal, MS. In: Simpósio de Geotecnologias no Pantanal, 1, Campo Grande, Brasil, Anais, p.175-181.

Facincani E.M. 2007. Geomorfologia e Geologia do Cenozóico do Médio Vale do Rio Aquidauana, Borda Sudeste da Bacia do Pantanal, MS. Rio Claro, Tese de Pós-Doutoramento, Instituto de Geociências e Ciências Exatas, Universidade Estadual Paulista (Unesp), 100 p.

Junk W.J., Brown M., Campbell I.C., Finlayson M., Gopal B., Ramberg L., Warner B.G. 2006. The comparative biodiversity of seven globally important wetlands: a syn- thesis. Aquatic Sciences, 68:400-414.

Leier A.L., DeCelles P.G., Pelletier J.D. 2005. Mountains, monsoons, and megafans. Geology, 33:289-292.

Mendes D. 2008. Filtros passa-baixas ponderado e dados SRTM aplicados ao estudo do Pantanal da Baixa Nheolândia, MS: aspectos tectônicos e de distribuição de lagoas hipersalinas. São Paulo, Dissertação de Mestrado, Universidade de São Paulo, Instituto de Geociências, 67 p.

Paranhos Filho A.C., Lastoria G., Torres T.G. 2008. Sensoriamento remoto ambiental aplicado: introdução às geotecnologias. Campo Grande, Ed. UFMS, 198 p.

Stanistreet I.G. \& McCarthy T.S. 1993. The Okavango Fan and the classification of subaerial fan systems. Sedimentary Geology, 85:115-133.

Tricart J. 1982. El Pantanal: un ejemplo del impacto geomorfologico sobre el ambiente. Informaciones Geograficas (Chile), 29:81-97.

Valeriano M.M. 2008. Topodata: guia para utilização de dados geomorfológicos locais. São José dos Campos, SP: INPE: Coordenação de Ensino, Documentação e Programas Especiais (INPE-15318-RPE/818), (Boletim), 72p.

Zani H. 2008. Mudanças Morfológicas na Evolução do Megaleque do Taquari: Uma Análise com Base em Dados Orbitais. Rio Claro, SP, Dissertação de Mestrado, Instituto de Geociências e Ciências Exatas, Universidade Estadual Paulista, 85 p.

Zani H., Assine M.L., Araujo B.C., Merino E.R., Silva A., Facincani E.M. 2006. Lobos deposicionais na evolução do megaleque do rio Taquari, Pantanal Mato-Grossense. In: INPE, Simpósio de Geotecnologias no Pantanal, 1, Campo Grande (MS), Brasil, Anais, p.285-292.

Manuscrito ID 14682 Submetido em 30/06/2009 Aceite em 05 de maio de 2010. 